\title{
TORSION OF THE FALLOPIAN TUBE
}

\author{
By Maurice Hershman, F.R.C.S. \\ Senior Surgical Registrar, Wordsley Hospital
}

It is considered worth while to record the following cases and to discuss briefly the subject of torsion of the Fallopian tube.

The first patient, a girl aged $\mathrm{I}$ 7, was admitted to hospital on December 26, I95 I, complaining of pain of four days' duration localized to the right iliac fossa. It was continuous and of a nagging type and had gradually got worse. She had been carrying out her normal occupation as a machinist but had felt unable to do so the day of admission and had vomited for the first time the previous day. Close questioning did not reveal any other symptoms. The bowels had been open normally, micturition was normal and the periods were regular. Her last period ended eight days before admission.

On examination she was not obviously in pain, her temperature was $100.4^{\circ}$ and pulse roo. There were no physical signs other than those of the abdomen, where there was tenderness and guarding in the right iliac fossa. Rectal examination showed tenderness on the right side. With a diagnosis therefore of appendicitis laparotomy was carried out. On opening the peritoneum there was found to be a considerable quantity of serous fluid. The appendix looked normal. Further search showed the right Fallopian tube to be twisted many times at the fundal end. The distal three-quarters of the tube was enlarged and haemorrhagicand the fimbrial end was completely closed off. The ovary was larger than normal. It was quite easy to remove the tube and leave the ovary. Appendicectomy was also performed. Convalescence was uneventful.

The pathology report, for which I am indebted to Dr. A. G. Marshall, was as follows:

'The first specimen is a Fallopian tube whose outline is continuous with a cystic mass lying towards its extremity. The whole specimen is discoloured by strangulation. The cyst is lined by a membrane whose inner wall is granular. Section of the whole wall of the cyst shows it to consist largely of blood clot. A few islands of highly vascular tissue are seen but they are distorted by haemorrhage and oedema. The Fallopian tube lies in the wall and it is also disintegrated. There is no recognizable cellular lining to the cyst.

' The second is a vermiform appendix $6 \mathrm{~cm}$. in length, it has been opened to show a congested mucous membrane. The appendix shows haemorrhage and a reactive change in its mucous membrane. There is no inflammatory cellular infiltration and one wonders if the lymphoid tissue in the mucous membrane has reacted to the nearby lesion.'

The second patient, a housewife aged $2 \mathrm{I}$ with one child, was admitted on March 24, 1952, having developed pain in the right iliac fossa 36 hours before admission. She had vomited several times since the pain commenced and the latter had now become persistent. There had been an increased frequency of micturition since the onset. The periods were quite normal and the last one had commenced three days prior to the onset of pain. On examination she was tender in the right iliac fossa and tender in the pouch of Douglas. She was extremely obese and it was impossible to feel any mass. At laparotomy the right Fallopian tube was twisted approximately twice and was swollen, blue and tense. The fimbrial end was closed off. In the right ovary there was a small follicular cyst present. The left tube and ovary showed many adhesions between the ovary and the tube. The ovary was a little enlarged but otherwise normal. Right salpingectomy was carried out and the right ovary left intact. The caecum and appendix were examined and a very small appendix remnant was not disturbed. Many adhesions were found running from the right iliac fossa into the pelvis. The abdomen was closed in the usual way.

The pathology report was as follows:

'The specimen consists of a right Fallopian tube which has undergone torsion at the uterine end. The whole organ appears to be infarcted. It takes the form of a hydrosalpinx and measures ro by 7 by $5 \mathrm{~cm}$. When divided it is filled with 


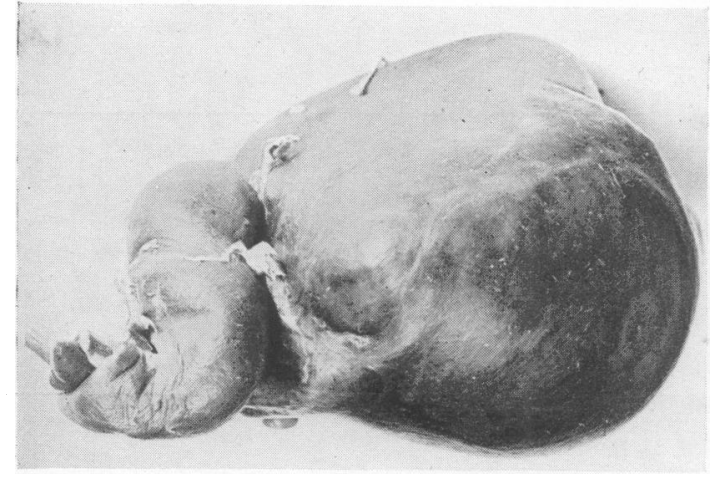

Operation specimen from the second patient

bloody fluid and blood clot. Section shows the whole tissue to be densely infiltrated by extravasated blood and only small fragments of it are recognizable. No structure resembling chorionic villi was found. Pathological diagnosis-hydrosalpinx infarcted through torsion.'

\section{Discussion}

Incidence. Torsion of the Fallopian tube may occur either with a normal tube or with a diseased tube. With a normal tube torsion occurs most commonly in patients who have borne children. The condition of rotation itself sometimes goes on to a spontaneous amputation. Anderson (1945) reported a case of torsion of a normal ovary and spontaneous amputation of the tube in a 12 year old girl.

Torsion of the diseased tube is the commonest variety of torsion and has long been recorded in the literature. Bland Sutton (1890) recorded a case of torsion associated with salpingitis and from 3 this time on there have been many reviews, in- $\stackrel{\mathbb{2}}{\Omega}$ cluding those by Anspack (I912) who recorded 95. cases, 62 of which were associated with hydrosalpinx, and Regad (1933) who recorded 201 cases from the literature, and of these 18 per cent. were associated with hydrosalpinx and approximately I3 per cent. were associated either with salpingitis or ectopic gestation.

Clinically. Nixon (1948) states that the fundamental features are the occurrence simultaneously of pain and vomiting associated with a palpable mass. However, this was not so in the first case, the vomiting occurring three days after the pain commenced. The patient being a virgin a vaginal examination was not carried out. The condition is said to be more common on the right than on the left. The explanation given is that the sigmoid colon on the left interferes with torsion.

\section{Summary}

Two cases of torsion of the Fallopian tube are recorded, one occurring in a girl of 17 with apparent normal tube and normal adnexa and the second case occurring in a young married patient with a previous history of an appendix abscess and a hydrosalpinx which had undergone torsion.

I wish to thank Dr. A. G. Marshall for the pathology reports and Mr. J. C. Newboldọ for permission to deal with both these cases.

\section{BIBLIOGRAPHY}

ANDERSON, H. E. (1945), Am. F. Obst. E.Gynec., 49, 283. ANSPACK, B. (1912), Am. F. Obst., 66, 553.

NIXON, W. C. W. (1948), British Surgical Practice, 4, 60. REGAD, J. (1933), Gaz. d. Hop. Paris, 106, 517 and 557. SUTTON, J. B. (1890), Lancet, ii, 1206.

\section{RUTHIN CASTLE, NORTH WALES}

A Clinic for the diagnosis and treatment of Internal Diseases (except Mental or Infectious Diseases). The Clinic is provided with a staff of doctors, technicians and nurses.

The surroundings are beautiful. The climate is mild. There is central heating throughout. The annual rainfall is 30.5 inches, that is, less than the average for England.

The Fees are inclusive and vary according to the room occupied.

For particulars apply to THE SECRETARY, Ruthin Castle, North Wales. 